\title{
Health Care Insurance System in the Republic of Albania and Development Perspective
}

\author{
Fjoralba Memia, (PhD candidate) \\ European University of Tirana \\ fmemia@hotmail.com
}

\section{Doi:10.5901/jesr.2015.v5n1p49}

\begin{abstract}
Health is a critical component of sustainable human development. It is an important part of people's physical, mental and social well being, and at the same time it has a long-term impact on social and economic development. In the framework of the government's strategy regarding the improvement and strengthening of health services is establish a mandatory health care insurance scheme in Albania. The right to health care is a fundamental right of a social - economic character and aims respect of human rights, equality and social justice. Albanian model of health insurance has realized this right preferring to keep in harmony legislation and institutions responsible for the organization and implementation of the right to health insurance. The compulsory health insurance scheme intends coverage of the population with health care services and specifies the main principles on which the health insurance scheme is set up, that is contributions and the principle of solidarity. In this paper, we analyze the recent developments and current situation related to legal and institutional bases for health care insurance system development in the Republic of Albanian, as well as to reach recommendations for its improvement in the near future.
\end{abstract}

Keywords: health care insurance system, insured person, benefits

\section{Introduction}

Health insurance is insurance against the risk of incurring medical expenses among individuals. By estimating the overall risk of health care and health system expenses, among a targeted group, an insurer can develop a routine finance structure, such as a monthly premium or payroll tax, to ensure that money is available to pay for the health care benefits specified in the insurance agreement. The benefit is administered by a central organization such as a government agency, private business, or not-for-profit entity. According to the health insurance law in Albania, the health insurance is defined as coverage that provides the benefits of health care.

According the Law no.10383, dated 24.02.2011, "On compulsory healthcare insurance in the Republic of Albania", as amended, the compulsory insurance finances the compulsory insurance services packages that include:

a) medical check-ups, examinations and treatment in public primary health care centers and public hospitals;

b) medical check-ups, examinations and treatments in private primary health care and hospital providers.

c) drugs, medical products and treatments by contracted providers of health services.

Compulsory health insurance is based on the contributions of employees, employers, state and other sources for other people, as provided for in this law, based on the principle of solidarity. Compulsory health care insurance scheme intends to cover the population with health care services, financed by the public and private sector, according to health insurance law.

\section{A Brief Historic Overview of the Health Care Insurance Scheme}

In 1991 the health status of the population in Albania is similar as in the other countries of South-Eastern Europe, but is lagging behind the EU countries.(Igor 2008) However, the health care sector is faced with several challenges associated with the improvement of the population's health status, the provision of basic benefits package, delivery of health services, public health, planning, management and development of human resources, quality assurance, health financing, and provision of a sustainable system of health care insurance.

(Yvone 2009, Health insurance systems in comparison- Differences and Common Denominators)

The health insurance scheme was developed pursuant to Law no. 7870, dated 13.10.1994 "On Health Insurance in the Republic of Albania". It covered a basic list of reimbursable drugs and payment of family doctors in the public system since the beginning. 
Thus, after the enforcement of the scheme under Law No. 7870 dated 13.10.1994, health insurance covered only a fraction of the price of medicines and service costs by a GP or family doctor. In 2002, after the amendements introduced to Law 8961 dated 24.10.2002, the specialist doctor, health care nurses were included in this coverage for all insured. In 2004, Law no. 9207 dated 15.3.2004 provided for the extension of the scheme in unique and tertiary examination services and medical consultations. In 2005, the law no. 9368 dated 7.4.2005, was amended and it included coverage of tertiary unique medical treatments into the scheme. The another change, which actually completes the extension of the scheme was introduced by the Law no. 10043 dated 22.12.2008 under which mandatory health insurance cover also hospital health services.

As the scheme evolved gradually, the number of services it covered was enhanced until it passed from undifferentiated financing to payment for health services packages. Health insurance scheme model in the Republic of Albania is Bismarck scheme,(OECD health 2008) which is based on mandatory and voluntary contributions, as well as funding from the state budget.

Economically active population pays health insurances, while state budget funds (which come from general taxation) cover inactive population and categories in need, something that indicates that the scheme is based on the principle of solidarity. (Law no.7870, 1994)

Health insurance scheme is based on the model of the single payer, which is the Compulsory Healthcare Insurance Fund that manages the scheme in compliance with healthcare national policies.

\section{Ongoing and Planned Health Care Insurance Reforms}

There are three key development challenges and opportunities for the Albanian health insurance sector:

- Achieving sound public expenditure management, especially through an increased emphasis on extra budgetary institutions which includes the HIF;

- Assuring undisrupted delivery of health services in the context of decentralization;

- Guaranteeing the quality, efficiency and access to health services.(World Bank Report 2009)

In order to meet the demands for high quality accessible health care, the National Health Care Strategy recently adopted by the Government has launched the following basic priorities in the health sector: improvement of the population health status, increased efficiency and efficacy of the health care system through institutional and structural reforms in the health care provision, modernization of public health care system according to the EU standards, improved planning of the human resource base in the health sector and introduction of quality assurance system, and last but not the least, reforming healthcare financing by introducing stronger accountability and transparency and linking the financing to better healthcare outcomes.

In this context the Albanian parliament approval the Law No. 10383 dated 24.02.2011 "On compulsory health insurances in Albania ". (This law, have enforced two years after its publication in the Official Gazette).According this law, The Compulsory Health Care Insurance Fund is only autonomous public body that provides and manages the provision of mandatory health care insurance in the Republic of Albania. The Fund is a specialized financial organization that manages the health care insurance scheme in coordination with national health care policies established by the Ministry of Health. The Fund is not a health institution. Although the Fund is obliged to execute the strategy of the Ministry of Health, it is entitled to develop management plans in the field of health insurance. But, it has to report to the Ministry of Health as far as their implementation is concerned.

\section{The Principles and Subject of Health Insurance Scheme in Albania}

The right to health insurance of citizens is included in the group of economic and social rights in the Constitution. This right is a positive one just like most of the rights that are part of this group.(Constitution of the Republic of Albania 1998) This conclusion is arrived based on the reference made by constitutional provisions when it conditions the application of this right to a special law which shall establish rules and its application procedure. Compulsory healthcare insurance scheme aims at health care coverage of the population through the following principles:

- Mandatory and voluntary insurance;

- Solidarity;

- Equal access for all citizens;

- Efficiency and quality in health care service financing;

- $\quad$ Free choice of the doctor; 
- $\quad$ Partnership relations between the purchaser, provider and beneficiary

Compulsory healthcare insurance and related contributions payments are mandatory for all economically active persons, residing permanently in Albania as, employees, self-employed persons, unpaid family workers and other economically active persons.

The Compulsory healthcare insurance covers, also, the following categories of economically inactive persons, whose payment of contributions is financed from the State Budget or other sources as provided for in the law:

- Persons who benefit from Social Insurance Institute;

- Persons who receive social assistance or disability payments in accordance with relevant legislation;

- Persons registered as unemployed - job seekers in the National Employment

- Service;

- Foreign nationals that are asylum seekers in the Republic of Albania;

- Children under 18 years;

- Pupils and students under the age of 25 years, provided they do not have income from economic activities;

- Categories of persons as defined by special laws.(Law no 10383, 2011)

Persons who are not included in compulsory health care insurance are entitled to voluntarily join the compulsory scheme. Voluntarily insured persons have the same rights and obligations as persons subject to compulsory insurance. Participation in the scheme is based on the payment of contributions. All persons participating in the scheme are considered insures. Health insurance contributions are personal, so it cover only the person who pays or which pays the contribution and not cover their member of families.

\section{Benefits of Mandatory Health Care Insurance Scheme}

Albanian nationals and foreigners, who are beneficiary of health care services, benefit a portion of the price of drugs, the primary health care and hospital services.

From a legal perspective, the relevant laws cited above, authorize the Council of Ministers that in all cases of the scheme expansion regulate in detail the specific types of health services to be included in the health insurance scheme according to specifications provided for by law. At the level of primary health care persons must not pay for the visit at the Health Centers,(DCM 857,2006)

The scheme is covering primary care services at health Centre level, including physician visits, examinations, simple diagnostics, referrals to specialized care, and other services available at health Centre level. Outpatient specialist care is also covered regardless of the type of specialist and the underlying health problems, including the referral and a treatment proposal.

For accessing any health benefit covered by Compulsory Health Care Fund (Fund), insured have to register with a family physician in a health centre, usually in the closest by facility. However, insured are free to choose their family physician. When an applicant shows up at the health centre, GPs revise updated contribution payment and then provide the new insured with a serial number that will form part of the final registration number. Thereafter, insured persons become entitled to benefits when they present the serial number at the Fund branch and receive an individual insurance booklet.

Coverage of unique tertiary examinations, otherwise known as coverage of expensive equipment, which are located in university level hospitals, is regulated in detail with DCM. No. 383, dated 19/06/2004 "On the approval of procedures, fees and the extent of coverage of unique and tertiary service included in health insurance." We mean here the screening services such as scanner, magnetic resonance, coronarographia etc. This Act sets out the conditions and procedures for benefiting. This service will be provided to those insured persons owning the health booklets and observing the recommendation system starting from the family doctor, specialist etc. The Council of Ministers has defined groups of insured persons who receive this health service free of charge and those who receive it through copayment. Thus, children up to 12 years old, totally disabled and war veterans as well as TB and CA patients profit the health service coverage cost at a rate of 100 percent, while other economically active categories are covered at a rate of $90 \%$ and $10 \%$ are covered by co-payments. The insured person who have not respected referral system pay the full cost.In cases when people are not insured/covered for their health care, there is an another approach according to the level of the health care. At the level of primary health care persons must pay a small fee(8-10€) for the visit at the Health Centers, and pay the full price for all the drugs needed and tertiary unique examinations care levels.(Order Ministry of Health)

At the hospital, unsured persons pay a fee per visit and they also pay a small fee in cases when they need to be 
hospitalized, but for the cost of the drugs and other expenditures in the hospital the bill is covered by the Compulsory health insurance fund.Medicine benefits are explicitly defined according to the "Fund List of Reimbursed Drugs" containing different categories of medicaments and various options per category. This list is conceived based on the international classification system ATC (anatomic, therapeutic and chemical) and contains 477 drugs. (Annual DCM reimbursement list drugs)This list, which cover a large number of diagnoses and more specifically are oral anti-diabetics; drugs for children with diabetes and hormonal disorders; antithrombotic in vassal surgery, drugs for cardiac therapy, drugs for patients with prostate, drugs for patients with hepatitis, drugs for palliative care etc. The reimbursed drugs price will be covered at a rate of $50 \%$ to $100 \%$, social categories such as pensioners, full disabled people, children 0-12 months, patients suffering from CA, TB, orphans, blind people will benefit free of charge the first alternative of each drug included in this list. Social categories such as veterans and war invalids benefit $100 \%$ free all the drugs in the reimbursable drugs list and those registered in the Republic of Albania.It has to be pointed out that entitlement to benefits is not linked with contribution payment. Having paid the due health insurance contributions does not automatically entitle Albanian citizens to health benefits because access to covered services requires a second active step from enrollees, namely to register with a family physician.

\section{Registration and Identification of Persons Insured by the Compulsory Health Care Insurance}

The categories of insured persons dividing them by their status into economically active, economically inactive and insured volunteers. Compulsory Healthcare Insurance Fund has began to create the registry of insured people where it records all insured persons in compulsory health care insurance by respective categories. In order that the registration and data for the insurance features per each person are complete, those institutions that are obliged to make registration and deliver data by categories of insurance.(DCM 306, 2014)

Thus, data for economically active persons will be obtained from the General Directorate of Taxation. Data on economically active persons are provided by a range of responsible institutions that represent different groups. So, SII is responsible for providing information on the category of people who benefit from social insurance schemes, as well as the category of self-employed persons in the village and unpaid persons of their family. On the other hand, the State Social Service which is responsible for persons receiving economic aid, the people who benefit payment for disability, blind and orphans etc. provides its respective information.

Data provided from Health Centers, which identify population registered with family doctors, a process that is currently monitored by health insurance structures, are also another important source of information. Persons insured in the compulsory health care insurance scheme will be identified through the Booklet/ Health Card. Booklet / Health Card is a document certifying that the holder is a person insured under law no. 10383, dated 24.02.2011, "On compulsory healthcare insurance in the Republic of Albania", as amended.

\section{Conclusions}

In the context of health insurance scheme we see that systems are based on financing of health care providers, ambulatory, hospital and pharmacist(rimburesement list drugs).

From this overview of the compulsory insurance scheme health care, we conclude that the right to health insurance as a social-economic right, guaranteed not only by the constitutional provisions but also by specific legislation. Health insurance is a compulsory and universally insurance scheme and as covering all citizens with permanent residence in Albanian. Participation in the scheme is based on the payment of contributions.Compulsory health insurance is based on the contributions of employees, employers, state and other sources for other people, as provided in compulsary health care insurance law, based on the principle of solidarity.Employers, for themselves and their employees, self-employed and unpaid family workers are responsible for the accurate calculation and payment of contributions, under the terms stipulated in the legislation about the collection of compulsory health and social contributions. Voluntary health insurance is paid from the person by his/her own and they bind a contract with the Fund concerning voluntary health insurance.Contributions for persons referred to categories economically nonactive people are paid by the state.All persons participating in the scheme are considered insures. Health insurance contributions are personal, so it cover only the person who pays or which pays the contribution and not cover their member of families.Persons insured in the compulsory health care insurance scheme will be identified through the Booklet/ Health Card. 


\section{References}

DCM no. 383 "Approbation of procedures, fees and cover rate for uncial and tertiary examination that are included in the health insurance",2004

DCM no.87" Administration and covering of the expenses for the reimbursement prescription" (amended),2006

DCM no. 857, "On the financing of primary health care services from the scheme compulsory health insurance" (2006).

DCM no. 140, "On the financing of hospital care scheme mandatory health care Insurance" (2010)

DCM no. 86, "The health Booklet" (2003)

European Code of Social Security, Strasbourg, (1996).

Dr. Paul Schoukens, European Union competencies in the field of social security, EU publication.

Elizabeth Doctor and Howard Oxley. "Health-Care Systems: Lessons from the Reform Experience". OECD (2007).

Health policies, a list of latest publications by OECD.

Lindenlaub Yvonne, Manthei Galina and Schulte Ortwin, EU - Health insurance systems in comparison- Differences and Common

Denominators -A Study for the GTZ Consultancy Project on Health sector reform in Albania, Berlin, (2008).

Law no.8417 dt 28.10.1998 Constitution of the Republic of Albania.

Law no.7870,"Health Insurance in the Republic of Albania "amended(1994)

Law no. 10383, "On compulsory healthcare insurance in the Republic of Albania"(2013)

OECD Health: Statistics and Indicators for 30 Countries, (2008).

Overview of Health Care Financing". World Health Organization, retrieved August( 2008

Prof. Dr.Denny Pieters, Social security system of Albania.

Regional Overview of Social Health Insurance in Europe, World Health Organization

Witter Sophie and Ensor Tim, An introduction to health economics 
